NBER WORKING PAPER SERIES

\title{
INTERNATIONAL CAPITAL MOBILITY, PUBLIC INVESTMENT AND ECONOMIC GROWTH
}

Richard H. Clarida

Working Paper No. 4506

\section{NATIONAL BUREAU OF ECONOMIC RESEARCH 1050 Massachusetts Avenue \\ Cambridge, MA 02138 \\ October, 1993}

I would like to thank Ron Findlay, Philippe Weil, and especially Martin Feldstein for their comments and suggestions. Any remaining confusions are my doing. This paper is part of NBER's research program in International Trade and Investment. Any opinions expressed are those of the author and not those of the National Bureau of Economic Research. 
NBER Working Paper \#4506

October 1993

\title{
INTERNATIONAL CAPITAL MOBILITY, PUBLIC INVESTMENT AND ECONOMIC GROWTH
}

\section{ABSTRACT}

This paper presents a neoclassical model of international capital flows, public investment, and economic growth. Because public capital is non-traded and is imperfectly substitutable for private capital, the open economy converges only gradually to the Solow steady-state notwithstanding the fact that international capital mobility is perfect. Along the convergence path, the economy initially runs a current account deficit that reflects a consumption boom and a surge in public spending. Over time, the rate of public investment declines as does the rate of growth in the standard measure of multifactor productivity in the private sector, the Solow residual.

In the empirical section of the paper, we test the hypothesis that the log of the Solow residual and the log of the public capital stock in the US, France, Germany, and Britain are cointegrated using the multivariate maximum likelihood approach of Johansen (1991). We find that productivity and public capital are cointegrated in each of these four countries. The estimated relationship between productivity and public capital is quite similar across countries. These results do not convey any information regarding causality. One plausible interpretation of our empirical finding of cointegration betven productivity and public capital is that productivity is exogenous with respect to public capital, but that public capital is not exogenous and is thus Granger caused by productivity. We test this hypothesis, and we find that it can be rejected for all four countries. However, there is also evidence that public capital is not exogenous with respect to measured productivity. We conclude that the structural relationship between public capital and productivity needs to be further investigated in light of the cointegration and causality results reported in this paper.

\author{
Richard H. Clarida \\ Department of Economics \\ Columbia University \\ 420 West 118 th Street \\ New York, NY 10027 \\ and NBER
}


INIERNATIONAL CAPITAL MOBILITY, PUBLIC INVESTMENT, AND ECONOMIC GROWIH

by

Richard H. Clarida

Columbia University

and

The National Bureau of Economic Research

1. Introduction

Recently, and on both sides of the Atlantic, economists have begun to reassess their thinking about international capital mobility and economic gronth. In Europe, there is an obvious interest in identifying and measuring the "growth effects of 1992", the steady-state gains to be derived from an integrated market in which goods and capital can move freely across national borders (Baldwin (1992): Clarida and Findlay (1993)). In the US, the 1992 presidential election focused voter - and academic - attention on the relationship among public investment, international capital flows, and productivity growth. At least three prominent proponents of the view that national public investment policies have a role to play in raising productivity growth and wages have been named to senior policymaking positions in the Clinton administration.

In a world in which capital is internationally mobile, capital deepening is not limited by national saving. It follow's that the process of convergence to the Solow steady-state in a small open economy should be quite rapid - indeed theoretically instantaneous - and that current account deficits financed by 
capital inflows can provide the capital deepening required to equate domestic and required world rates of return (Barro, Mankiv, and Sala-i-Martin (1943)). Notwithstanding this theoretical implication of international capital mobility and the Solow growth paradigm, OECD economies appear to converge quite slowi: to their respective Solow steady-states (Mankiw, Romer, and Weil (1991): Helliwell (1993)). Barro, Mankiw, and Sala-i-Martin (1993) explicitly consider this tension between the apparently high degree of capital mobility among countries and the sluggish convergence of rates of economic to the solow steady-state.' They show that if international capital mobility is to some degree imperfect for example, if the outstanding stock of foreign debt cannot exceed the value of the domestic capital stock - then the optimal Ramsey accumulation path features the gradual convergence to the steady-state observed in the data.

While the evidence presented in Feldstein and Horioka (1980) indicates that international capital mobility is far from perfect, recent research by obstfeld (1987) indicates that the degree of capital mobility among the major OECD countries may be quite high (although see Feldstein and Bacchetta (1991) for contrary evidence). In Section 2 of this paper, we present a neoclassical model of optimal economic growth in a world of perfect international capital mobility which features the sluggish convergence to the steady-state evident in the data. Our framework augments the traditional solow model by including productive public capital in the aggregate production function. In our model. public capital and private capital are not perfect substitutes. Public capital goods are nontradable and must be produced with private capital and labor. The government is assumed to select the time path of public investment to maximize the present value of lifetime household utility, and to finance public investment with a lump sum tax on household income. 
The model has a number of interesting implications. Along the optimal convergence path to the Solow steady-state, the rate of public investment declines as does the rate of growth in the standard measure of multifactor productivity in the private sector, the Solow residual. These implications are consistent with the empirical evidence reported in Aschauer (1989) for US data and Ford and Poret (1991) who study the OECD countries. Because of perfect capital mobility, the rate of return on private capital is constant and equal to the world level along the convergence path, as is the capital-output ratio. The constancy of the capital-output ratio during the process of economic development has been emphasized by Kaldor (1961) and is inconsistent with the predictions of the neoclassical growth model in a world without capital mobility. In our framework, as public capital is accumulated, the private domestic capital stock consistent with the required world rate of return is rising due to the complementarity between the public and private capital stocks. The growth in public and private capital raises real wages along the optimal convergence path. Foreseeing this rise in wages, household initially seek to borrow from abroad to finance consumption that exceeds current income. This dissaving by households. along with the public investment plans of the government and the private investment that will flow in to equalize domestic and world rates of return on private capital, implies that the country must initially. run a current account deficit along the optimal convergence path. This is so even if, as we assume. the government balances its budget each period by collecting taxes equal to the current cost of public investment. Thus the initial current account deticit that emerges during the transition to the steady-state reflects a consumption "boom" relative to current income, a consumption boom that generates in a shortfall of private saving relative to private investment. 
In Section 3 of this paper, we investigate empirically the relationship between public capital and multifactor productivity in the US. Germany. France. and the United Kingdom. We find that we cannot reject the hypothesis that the logarithm of the public capital stock and the logarithm of multifactor productivity in all four countries are integrated I(1) stochastic processes. This suggests that a regression of productivity on public capital (Aschauer (1989)) will be spurious in the sense of Granger and Newbold (197/) unless public capital and the Solow residual are cointegrated. Even if public capital and productivity are cointegrated, OLS estimates of the regression coefficient, while consistent, will be biased, and OLS standard errors will be inappropriate for hypothesis testing (Campbell and Perron (1991)).

We formally test the statistical hypothesis that the log of the Solon' residual and the $l o g$ of the public capital stock in each country are cointegrated using the multivariate maximum likelihood approach of Johansen (1991). We find that we can reject the null hypothesis of no cointegration in favor of the alternative hypothesis that productivity and public capital are cointegrated in each of the four countries. Somewhat to our surprise, the estimated relationship between public capital and productivity is quite similar across countries.

While these results indicate that the empirical correlation between the Solow residual and public capital is not spurious, they do not convey any information regarding causality. In particular, one plausible interpretation of our empirical finding of cointegration between productivity and public capital is that productivity is exogenous with respect to public capital. but that public capital is not exogenous and is thus Granger caused by productivity. We formally 
test this hypothesis for each country, and we find that it can be rejected for all four countries. Notwithstanding the ex ante plausibility of the hypothesis that productivity is exogenous with respect to public capital. there is substantial statistical evidence against this hypothesis in the US. French. German, and British data. However, there is also evidence, especially in the German and British data, that public capital is not exogenous with respect to measured productivity. We conclude that the structural relationship between public capital and productivity needs to be further investigated in light of the cointegration and causality results reported in this paper.

Barro (1990) and Barro and Sala-i-Martin (1991) have included government provision of productive public services in an endogenous growth model. Their focus is on the relationship among productive government services, the distortionary taxes levied to pay for them, and long run growth in a closed economy. These papers do not take into account that many productive government services are in fact yielded by a stock of productive public capital that is accumulated over time. Imperfect substitutability between public and private capital stocks, by introducing a second state variable, will in general complicate analysis of transition dynamics in an optimizing model. We demonstrate that in a small open economy, the transition dynamics for the optimal accumulation of public capital decouple from the transition dynamics for the accumulation of tradeable wealth, comprised of private capital and international bonds which are perfect substitutes. This decoupling, which is reminiscent of the result presented in Blanchard and Fischer (1990), enables us to use a simple phase diagram to characterize the process of convergence to the steady-state. 
2. Capical Mebility. Public Investment, and Economic Growth: A Model

Consider a small open economy comprised of a representative household. a representative firm with access to a technology for producing final output $y(t)$. and a government with access to a technology for producing public capital $A(t)$. Final output can be either consumed or costlessly transformed into private capital. Household financial wealth $w(t)$ is comprised of private capital $k(t)$ and internationally traded bonds $b(t)$ which are perfect substitutes in international portfolios, yielding an instantaneous equilibrium return of $r$, the rate at which households discount future utility. The household supplies L hours of labor inelastically receiving a wage of $\omega(t)$. The government levies a lump sum tax of $T(t)$ each period to defray to cost public investment.

The household selects a time path for consumption $c(t)$ so as to:

$$
\max \int_{0}^{\infty} e^{-r t} u(c(t)) d t
$$

subject to:

$$
d w(t) / d t=r w(t)+w(t) L-T(t)-c(t)
$$

$$
\lim _{\mathrm{L}-\infty} e^{-\mathrm{r} w} \mathrm{w}(t)=0 \text {. }
$$

The solution to this problem must satisfy:

$$
u^{\prime}(c(\lambda(t)))=\lambda(t)
$$

$$
d \lambda(t) / d t=0 \text {. }
$$

That is, the household selects the maximum sustainable consumption $c(\lambda)$ given the intertemporal budget constraint. In particular:

$$
c(\lambda)=r w(0)+r \int_{a}^{\infty} e^{-r t}(\omega(t)-r(t)) d t
$$


To select $c(\lambda)$. the household must forecast the time path of wages and taxes. ie shall assume that expectations are rational. In the context of this small open economy, this implies that households must forecast the time path of public investment $i(t)$ and the time path of multitfactor productivity $a(t)$.

We begin with the production function of the representative firm:

$$
y(t)=a(t) k(t)^{1-6}(L-1(t))^{\theta}
$$

where $1(t)$ is the number of hours that the household works for the government. so that $L-l(t)$ is the number of hours that are supplied to the production of final output. Given the level of productivity $a(t)$ and the private sector labor supply $L-I(t)$, the supply of capital available to the firm is determined by the global capital market equilibrium condition that the marginal product of capital must equal $r+\delta$, where $\delta$ is the rate of depreciation. ive have:

$$
k(t)=(1-\theta)^{1 / \theta}(r+\delta)^{-1 / \theta} a(t)^{1 / \theta}(L-L(t)) .
$$

Substituting for $k(t)$. we obtain an expression for private domestic product:

$$
r(t)=k a(t)^{1 / \theta}(L-L(t)):
$$

where $k=(1-\theta)^{-i+: / \theta}(r+\delta)^{1-1 / \theta}$. Given labor's share of $\theta .(9)$ implies that the equilibrium wage is just:

$$
\omega(t)=\theta k a(t)^{1 / \theta}
$$

Thus, the time path of wages in the small open economy is determined solely by the time path of multifactor productivity. Private saving has no influence on the time path of wages since the time path of $k(t)$ is determined by the time path of technology and the private labor supply. 
We assume that the level of multifactor productivity in the private domestic product production function is an increasing function of the public capital stock (Aschauer (1989); Barro (1990)):

$$
a(t)=(k \theta)^{-\theta} A(t)^{Y}
$$

The stock of public capital evolves according to:

$$
d A(t) / d t=-\delta A(t)+i(t) .
$$

The government hires labor $l(t)$ and private capital $\kappa(t)$ to produce public capital goods according to the Cobb-Douglas production function:

$$
i(z \cdot A(t), I(t) \cdot \kappa(t))=A^{A} z^{1-\alpha} l(t)^{\epsilon} \kappa(t)^{\alpha-e}
$$

To produce a "road", the government combines workers. "tractors", a fixed factor $z$ such as "land", and existing roads. The cost minimizing bundle of inputs chosen to produce public capital will satisfy $\kappa(t) / 1(t)=((\alpha-\epsilon) / \epsilon) \omega(t) /(r+\delta)$. To ease notation, we shall assume $(\alpha-\epsilon) / \epsilon-1$. As will become clear. it is also convenient. but by no means necessary. to assume that $d=y(1-(\alpha-\epsilon)) / G$.

ie suppose that the government maximizes lifetime household utility (1) subject to (2), (3), (10), (11), (12), (13) and the balanced budget condition

$$
T(t)=\omega(t) l(t)+(r+\delta) \kappa(t)=2 \omega(t) 1(t)
$$

Let $\mu(t)$ denote the co-state variable for equation (12). Along an optimal path:

$$
\begin{aligned}
& 2 \lambda A(t)^{\gamma / \theta}=\mu(t) A(t)^{\gamma / \theta} z^{2-\alpha} \alpha(r+\delta)^{-\alpha / 2} l(t)^{\alpha-1}: \\
& d \mu(t) / d t=(\delta+r j \mu(t)-\mu(t)(\gamma / \theta) A(t)^{(\gamma-\theta) / \theta} z^{:-\alpha}(\tau+\delta)^{-\alpha / 2} I(t)^{\alpha} \\
&-\lambda(\gamma / \theta) A(t)^{(\gamma-\theta) / \theta}(L-21(t)) .
\end{aligned}
$$


The left hand side of (15) is just the marginal resource cost of an extra unit of public capital multiplied by the marginal utility of consumption, $\lambda$. which is constant along the optimal path. This must be equal to the marginal product of the resources diverted to the production of public capital multiplied by the shadow value of public capital, $\mu(t)$. The shadow value of public capital is. from (16), equal to the present value of the marginal social products of public capital multiplied by the marginal utility of consumption. $\lambda$ :

$$
\mu(t)=\int_{t}^{\infty} e^{-(s+\delta)(s-t)} \lambda(\gamma / \theta) A(s)^{(\gamma-\theta) / \theta} /(L-21(s))+21(s) / \alpha / d s
$$

Equation (15) can be solved for $1(t)$, yielding:

$$
I(\mu(t) / \lambda)-\left(\alpha(r+\delta)^{-\alpha / 2} z^{1-\alpha} \mu(t) / 2 \lambda\right)^{1 / 1-\alpha}
$$

Substituting into (13). we obtain an expression for optimal public investment:

$$
i(\mu(t) / \lambda ; A(t))=z A(t)^{\gamma / \theta}\left(\alpha(r+\delta)^{-\frac{3}{3}} \mu(t) / 2 \lambda\right)^{\alpha / 2-\alpha}
$$

According to equation (18), the rate of public investment $i(t) / A(t)$ is an increasing function of the shadow value of public capital and a decreasing function of the stock of public capital as long as $\gamma<\theta$.

We now investigate the stability properties of this dynamic system in $A(t)$ and $\mu(t)$ defined by equations (12) and (16). Substituting (18) into (12). we see that the $d A(t) / d t=0$ schedule is upward sloping,

$$
\partial \mu(t) / \partial A(t)_{i A(t) ; A t=0}>0:
$$

and that in a neighborhood of the steady-state $\delta A=z A^{\gamma / \theta}\left(\alpha(r+\delta)^{-\frac{\delta}{2}} \mu(t) / 2 \lambda\right)^{\alpha / 2-\alpha}$. $A(t)$ is stable given $\mu$. Tuming to the $d \mu(t) / d t$ schedule, we confine our 
attention to the empirically relevant case in which $\gamma<\theta$. This condition states that the elasticity of productivity with respect to public capital is less than the elasticity of private domestic product with respect to labor. labor's share. ie differentiate (16) with respect to $A(t)$ using (15) to find that if

$$
(\delta+r) \mu(t)-\mu(t)(\gamma / \theta) A(t)^{(\gamma-\theta) / \theta} z^{1-\alpha}(r+\delta)^{-\alpha / 2} 1(t)^{\alpha}>0:
$$

the $d \mu(t) / d t=0$ schedule will be downward sloping

$$
\hat{\sigma} \mu(t) / \partial A(t)_{\mid d u(t) / d t=0}<0 .
$$

From (16). it is evident that this condition must be satisfied in a neighborhood of the steady-state if $L / 2>l(t)$. $L(t)$ will be less than $L / 2$ in the steadystate if $\gamma$ is sufficiently small. Intuitively. the smaller is $\gamma$. the smaller is the marginal social product of government employment in the production of public capital, and thus the smaller will be share of total employment devoted to the production of public capital. It may also be verified by inspection of (16) that. given A, $\mu(t)$ is unstable. Thus, as shown in Figure 1. the system dynamics are characterized by a downward sloping saddle-path that lies everywhere bel ow the $d \mu(t) / d t=0$ schedule.

This model has a number interesting implications, several which can be read off the phase diagram. Starting from a modest initial stock of public capital $A(0)$. the shadow value of public capital $\mu(0)$ jumps in anticipation of the high marginal social product of public investment in present and future years. This triggers an inftial increase in public investment in excess of the rate required to replace depreciating public capital. The initial increase in public investment leads to the accumulation of public capital. which over time reduces the social product, and thus the shadow value. of additional public investment. 


\section{Dynamic Adjustment of Public Capital}

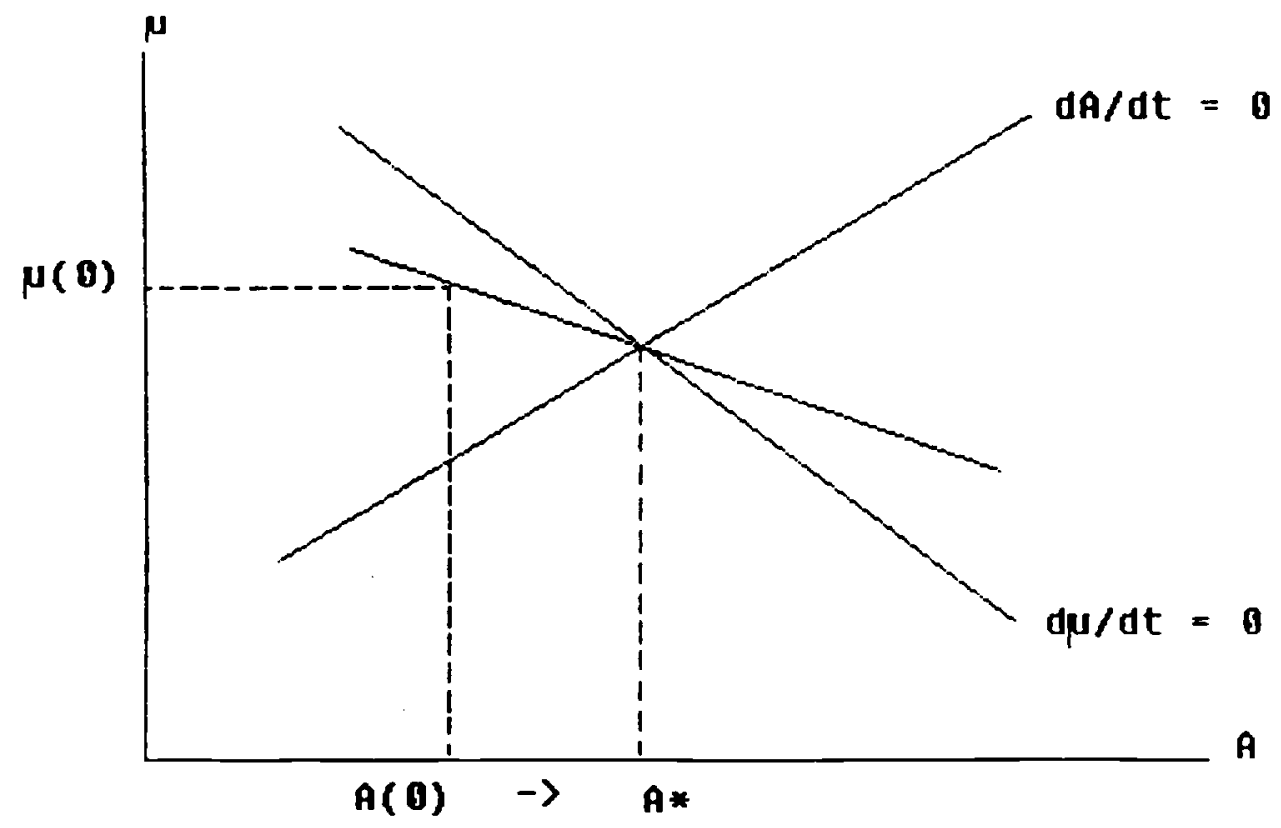


Given this decline in the shadow value of public capital. public investment begins to fall and in fact declines - relative to the initial public investrent surge - along the optimal convergence path to the steady state. Given the complementarity public capital. labor. and private capital embodied in the Aschauer-Barro production function for final output. these results can be used to characterize the time path of private multifactor productivity growth in the small open economy along the convergence path to the Solow steady state. In particular. from (12) and (18) we see that:

$$
\begin{aligned}
d \log (a(t)) & =-\delta \gamma+(\gamma / \theta) z A(t)^{\gamma / \theta-1}\left(\alpha(r+\delta)^{-t} \mu(t) / 2 \lambda\right)^{\alpha / 1-\alpha}: \\
& =\gamma d \log A(t) .
\end{aligned}
$$

which must falling over time since $A(t)$ is rising over time and $\mu(t)$ is falling.

The neoclassical credentials of this model are impeccable, and thus the intuition behind its implications is not elusive. Nonetheless, we would argue that these implications are not widely appreciated. In particular. the fact that the public investment rate in the lis (and other countries) has fallen over the past two decades has been decried as prima face evidence that government policy has failed to "put people first". In the context of our analysis. public capital accumulation is the sole source real wage gains as is clear from equation (10) and the fact that private capital accumulation cannot contribute to capital deepening in a world of perfect capital wobility. In fact. in this world capital deepening occurs solely because public capital accumulation raises the warginal product of private capital inducing capital inflows. or a reallocation of domestic wealth. sufficient to equalize domestic and world returns to private capital. From equations (8) and (11) we see that:

$$
d \log k(t) / d t-d \log (L-1(t)) / d t=d \log \omega(t) / d t=(\gamma / \theta) d \log A(t) .
$$


Given the objective of maximizing (1), the policymaker in this small open economy does "put people first" and does take into complete account that productivity. wages. and household welfare are directly and decisively influenced by the time path of public investment. In short, the evidence reported in Aschauer(1989) and Ford and Poret (1991) that a sustained decline in the rate of public investment has been associated with a slump in private productivity growth is, by itself, not inconsistent with the welfare maximizing accumulation of public capital.

Because of perfect capital mobility. the rate of return to private capital is constant and equal to the equilibrium world return throughout the process of convergence to the steady state. Using (8) and (9), we see that the capitaloutput ratio is also constant and equal to:

$$
k(t) / y(t)=(1-\theta) /(r+\delta) .
$$

The constancy of the capital-output ratio during the process of economic development has been emphasized by Kaldor (1961) and is inconsistent with the predictions of the one-good neoclassical growth model in a world without capital mobility.

In our framework. as public capital is accumulated, the private domestic capital stock consistent with the required world rate of return is rising due to the complementarity between the public and private capital stocks. The growth in public and private capital raises real wages along the optimal convergence path. Since public investment declines along the optimal convergence path. so do tax collections(!). Foreseeing this rise in wages and decline in taxes. households initially seek to borrow from abroad to finance consumption that exceeds current income. This dissaving by households, along with the public 
investment plans of the government and the private investment that will flow in to equalize domestic and world rates of return on private capital, implies that the country must initially run a current account deficit along the optimal convergence path (cf. Blanchard and Fischer (1989) Chapter 1) This is so even if, as we assume, the government balances its budget each period by collecting taxes equal to the current cost of public investment. Thus the initial current account deficit that emerges during the transition to the steady-state reflects a consumption boom relative to current income, a consumption boom that generates a shortfall of private saving relative to private investment.

Up until now, we have abstracted from exogenous technical progress so as to focus exclusively on the interplay between public investment, productivity growth. international capital flows, and the gradual convergence to the steady state in the open economy. Suppose, more realistically, that technical progress augments at rate $g$ the effective stock of the two factors in fixed supply so that $L(t)=e^{8 t} L$ and $z(t)=e^{8 t} z$. It is straightforward to verify that in this growing open economy, the steady state exhibits balanced growth with output. wages, private capital, and public capital all rising at the rate $g /(1-\gamma / \theta)$. Optimal public investment is given by:

$$
i\left(\mu(t) / \lambda ; e^{s t} ; A(t)\right)-e^{8 t} z A(t)^{\gamma / \theta}\left(\alpha(r+\delta)^{-t} \mu(t) / 2 \lambda\right)^{\alpha / 1-\alpha} .
$$

Let $A(t)=A(t) e^{-(B /(1-\gamma / \theta) t}$. Substituting (26) into (12). we see that the $d A(t) / d t=0$ schedule defined by:

$$
(\delta+g /(1-\gamma / \theta)) A(t)=z A(t)^{\gamma / \theta}\left(\alpha(\tau+\delta)^{-\frac{1}{\mu}} \mu(t) / 2 \lambda\right)^{\alpha / 1-\alpha}:
$$

is upward sloping and is stable in a neighborhood of the steady state. 
Along the optimal accumulation path the shadow value of public capital evolves according to:

$$
\begin{array}{cc}
d \mu(t) / d t-(\delta+r) \mu(t) & -\mu(t)(\gamma / \theta) A(t)^{(\gamma-\theta) / \theta} z^{1-\alpha}(r+\delta)^{-\alpha / 2} 1(t)^{\alpha} \\
& -\quad \lambda(\gamma / \theta) A(t)^{(\gamma-\theta) / \theta}(L-21(t)) .
\end{array}
$$

As demonstrated above for the case in which $g=0$, the $d \mu(t) / d t$ schedule will be downward sloping in a neighborhood of the steady state if $\gamma$ is sufficiently small. As before, the system dymamics are characterized by a downward sloping saddle path that lies everywhere below the $d \mu(t) / d t$ schedule. Along the path of convergence, the growth in the public capital stock declines until reaching its steady state rate of $g /(1-\gamma / \theta)$. Along the convergence path. the growth in private multifactor productivity:

$$
d \log a(t)=\theta g+r d \log A(t):
$$

must also decline until reaching its steady state rate of $g g /(1-\gamma / \theta)$. Implications for Europe

This model has several implications that pertain to the process of integrating the eastern European economies into the world's market - and especially EC - economies and trading system. The model sheds light on the process of growth and development in a small open economy that is able to benefit from international capital mobility. Notwithstanding the fact international capital flows insure that the return to private capital is at all times equal to the world return, convergence to the steady state growth path takes time as the economy only gradually accumulates the public capital needed to complement internationally mobile private capital and labor. The World Bank and the European Bank for Reconstruction and Development can play an important role in 
channeling funds and expertise to the most productive infrastructure projects in these countries. Traditionally. it has not been uncomron for the lending on such projects to be provided at a concessional interest rates. In the context of the model presented above, it is straightforward to demonstrate that. to the extent that a concessional interest rate lowers the rental cost of private capital employed in the production of public capital. the optinal rate of public investment, the equilibrium rate of private investment. and the speed of convergence to the steady state growth path increase.

Another implication of the model. discussed at length above. is that expectations of rising wages set off a "consumption boom" in an economy that initially finds itself with a public, and thus in equilibrium private. capital stock that is far below the steady state level. Of course, this consumption boom occurs in conjunction with a private investment boom and a surge in government spending and results in a current account deficit during the early stages of integration with the market economies and the global capital market. The conjunction of an initial consumption and investment boom and a rise in government spending might be difficult to interpret within the context of a Ramsey model of economic growth without capital mobility. In the Ramsey model. an initial investment boom occurs when the marginal product of capital is high relative to the rate of time preference. The high marginal product of capital encourages households to defer consumption to the future. Along the Ramsey adjustment path, consumption is initially low and rising while net investment is initially high and falling. By contrast, according to our model an initial splurge in consumption and government spending in conjunction with an investment boom does not necessarily represent an "excessive" demand for foreign capital inflows. 
The model also sheds light on the mechanism by which "the growth effects of 1992" may be achieved. In a perceptive paper, Baldwin (1992) argues that estimated static efficiency gains to European GDP arising from completion the 1992 program understate the

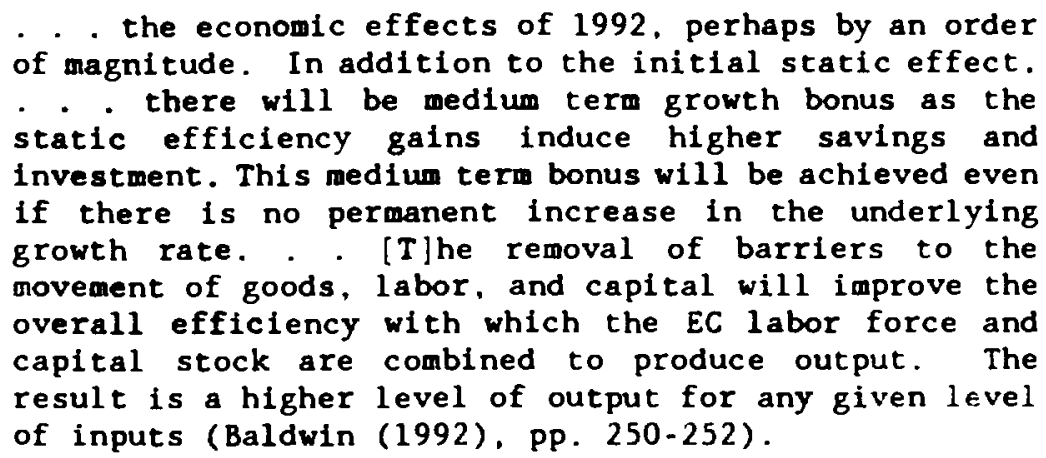

Baldwin conducts his analysis of the Solow growth model - he also studies an endogenous growth specification - under the assumption that capital is immobile so that the process of capital deepening that generates the "growth effects of 1992" must be financed by domestic savings. In such a world, the 1992 efficiency gains, by shifting up the aggregate production function, set in motion the traditional process of capital deepening and economic growth which gradually lifts the capital-labor ratio and the level of income. Baldwin shows that this "medium term growth bonus". the rise in income that follows from the endogenous accumulation of capital in the Solow growth model. can be at least as great as the "static efficiency effect", the initial shift in the aggregate production function.

In the context of our model, a shift in Europe's aggregate production function brought about by 1992 efficiency gains will boost the marginal product of private capital, inducing a capital inflow until the marginal product of private capital is driven down to the world level. This is just the medium term 
growth, or more precisely "private capital deepening". bonus in a world of capital mobility. But this is not the end of the story. Assuming that 1992 efficiency gains also shift the production function for public investment in each country, it is straightforward to verify that "public capital deepening" must also occur. Moreover, as each economy gradually accumulates public capital according to the dynamic process outlined above, the complementarity between public and private capital induces additional investment in private capital. We note finally that, according to (29), the growth in private multifactor productivity rises in response to the 1992 efficiency gains. and declines only gradually back to the steady state rate $\theta g /(1-y / \theta)$. 


\section{Empirical Results}

In a widely cited but controversial paper Aschauer (1989), running regressions of productivity on public capital using annual postwar US data, concluded that the productivity slowdown in the US can be "explained" by a roughly contemporaneous slowdown in the rate of US public investment. Ite also argued that cross sectional differences in average annual growth rates in the G7 countries appear to be associated with cross sectional differences in rates of public investment. Aschauer recognized that the endogeneity of the public capital stock makes it problematic to infer the direction of causality from the correlations his regression estimates recover and he attempted to control for it. but he concluded that his evidence was consistent with the hypothesis that public capital augments the US economy's aggregate production function, and that the slowdown in US public investment can account for as much as $80 z$ of the productivity slowdown.

Consider the equation $a(t)-A(t)^{\gamma} \exp \left(a_{0}+\epsilon(t)\right)$ which should be thought of as one equation from a simultaneous equations model. Taking logs:

$$
\log a(t)=a_{2}+\gamma \log A(t)+\epsilon(t) .
$$

In general, it is not possible to recover a consistent estimate of $\gamma$ from an OLS regression of $\log a(t)$ on $\log A(t)$ if $(30)$ is true. There are two cases to consider. If $\log a(t), \log A(t)$, and $\epsilon(t)$ are stationary stochastic processes. $\epsilon(t)$ will in general be correlated with $\log A(t)$. This is the standard simultaneous equations problem and OLS will be biased and inconsistent. If instead $\log a(t), \log A(t)$, and $\epsilon(t)$ are nonstationary unit root stochastic processes, an OLS regression of $\log a(t)$ on $\log A(t)$ represents a spurious regression in the sense of Granger and Newbold (1974). 
There is a special case in which it is possible to obtain a consistent estimate of $\gamma$ from OLS estimates of (30). This is the special case in which $\log a(t)$ and $\log A(t)$ are nonstationary in levels but stationary in first differences and in which $\epsilon(t)$ is stationary in levels. Under these circumstances, equation (30) represents a cointegrating relationship between $\log a(t)$ and $\log A(t)$. OLS is consistent but is in general biased, and OLS standard errors are, in general, incorrect (Campbell and Perron (1991)). Fortunately, Johansen (1991) has developed a maximum likelihood procedure for testing the hypothesis of cointegration. for estimating the cointegrating vector. and for testing exogeneity hypotheses. In this section of the paper. we employ the Johansen approach to investigate the statistical correlation between public capital and productivity using annual time series data for four countries: the United States, France, Germany, and Britain.

We test the unit root hypothesis with the augmented Dickey-Fuller t-test. Under the null hypothesis that a variable $x(t)$ is difference but not level stationary, the regression:

$$
\Delta x(t)=\mu_{0}+\mu_{1} t+\varphi x(t-1)+\rho_{1} \Delta x(t-1)+\ldots+\rho_{p} \Delta x(t-p)+v(t):
$$

is run, and a $t$-test of the significance of $\varphi$ is performed. Under the null. $\varphi=0$ and the $t$-ratio has a skewed distribution that has been investigated and tabulated by Fuller (1975). The results of this test applied to annual data on public capital and multifactor productivity for each country are reported in Table 1. There is no evidence at even the 10 percent level against the null hypothesis that each variable under study is nonstationary in log levels except UK public capital for which the hypothesis of a unit root can be rejected at the 10 percent, but not the 5 percent level. 
Proceeding under the working hypothesis that all of the variables are nonstationary in levels but stationary in first differences, we estimate bivariate vector error correction models (VECM) for log productivity and log public capital in each country. Letting $y(t)=[\log a(t), \log A(t)]^{\prime} \operatorname{denote}$ the 2 by 1 vector of the system's variables, the vector error correction model can be written:

$$
\Delta y(t)-\mu_{0}+\Gamma(L) \Delta y(t-1)+\Pi y(t-1)+\zeta(t)
$$

If the matrix $\Pi$ is of full rank $r=2$, the VECM reduces to the usual bivariate VAR in the levels of stationary variables. If the matrix $\Pi$ is the null matri: so that $r-0$, the VECM represents a VAR in first-differences. The bivariate VECM differs from the usual VAR in that it allows for the existence of a longrun equilibrium relationship between the system's variables. If the matrix $\Pi$ is of reduced rank $r=1$, it can be factored into the product of two 2 by 1 vectors $\varphi$ and $\beta$ such that:

$$
\Pi=\varphi \boldsymbol{\beta}^{\prime}
$$

where $B^{\prime}$ is the 1 by 2 cointegrating vector. and $\varphi$ is the 2 by 1 vector of adjustment coefficients for the system's 2 equations. The cointegrating vector defines a long run equilibrium to which the system ultimately returns after a shock. The parameter in each of the 2 rows of the vector determines the rate at which each of the system's 2 variables adjust in response to lagged deviations:

$$
z(t-1)=\beta^{\prime} y(t-1)
$$

from the cointegrating relationship. 
TABLE 1

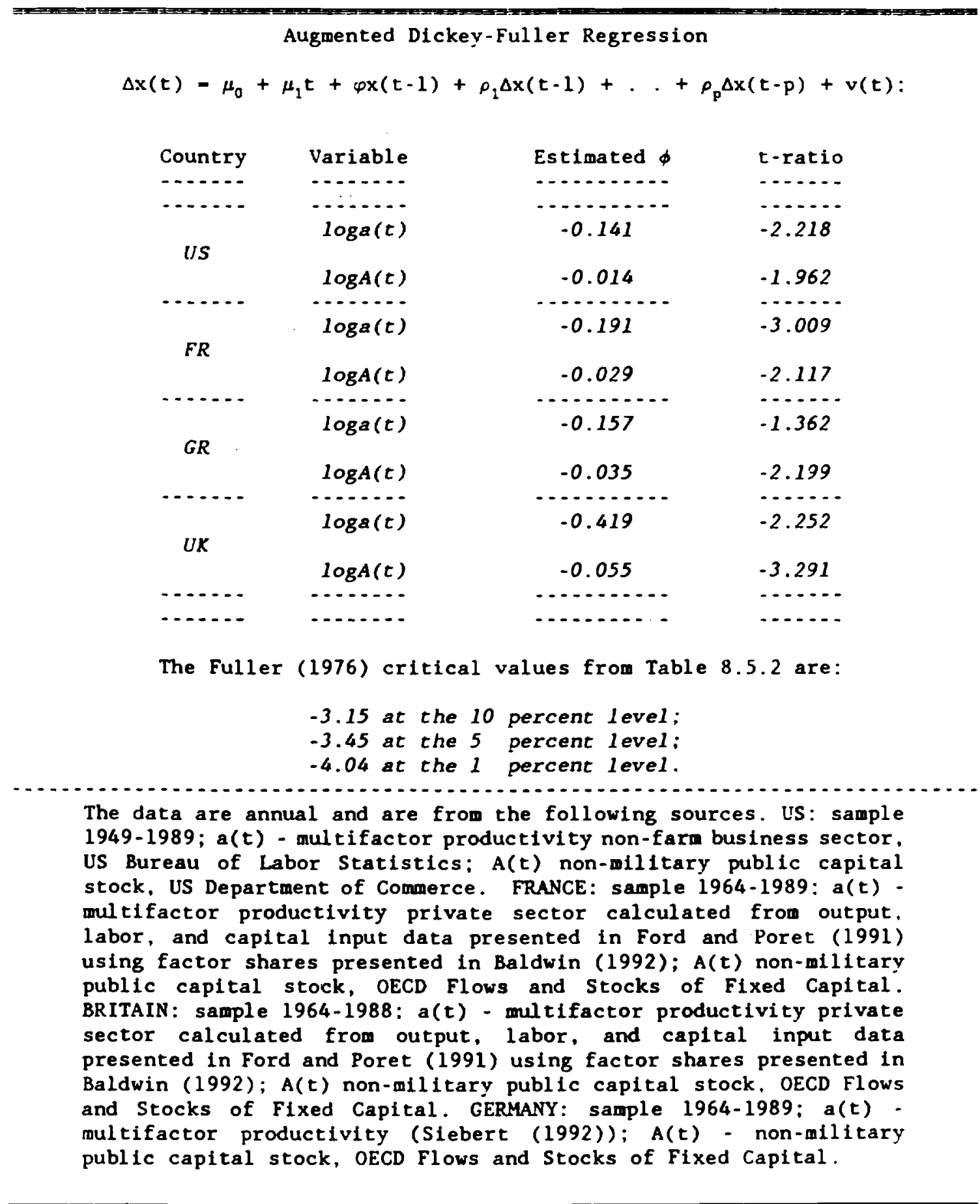


Table 2 presents the results of two tests developed by Johansen to investigate the hypothesis that the number of cointegrating vectors in a system of $n$ variables is less than or equal to equal to $r$. For the US, France, and Germany (Britain) and according to both the trace and the $\lambda$-max statistic, we can reject at the 5 percent ( 10 percent) level the hypothesis of no cointegration against the alternative hypothesis that loga(t) and $\log A(t)$ are cointegrated. A finding of cointegration implies that a regression of loga(t) on $\log A(t)$ is not spurious in the sense of Granger and Newbold, and indicates that an unbiased and efficient estimate of $\gamma$ can be obtained from the VECM for each country.

Table 3 presents for each country the Johansen maximum likelihood estimates of $\gamma$, the results of a likelihood ratio test of the hypothesis that $\gamma=0$, the estimates of the $\varphi$ vector of adjustment coefficients, and the results of likelihood ratio tests of the hypotheses that $\varphi_{1}-0$ or $\varphi_{2}-0$. As can be seen in the second column of the Table, the point estimates of $\gamma$, the elasticity of productivity with respect to public capital, range from 0.37 in the US to 0.48 in Germany. Moreover, the estimates for $\gamma$ in the US. France, and Britain are all clustered quite close to Aschauer's OLS estimate for the US of 0.39 . Each of these estimates of $\gamma$ is significantly different from 0 at the 1 percent level.

From the discussion in Ericsson (1991) and Johansen (1992). a necessary condition for productivity to be exogenous with respect to public capital is that the dynamic equation for productivity exhibit no error correction. That is, the exogeneity of productivity with respect to public capital requires that $\varphi_{1}-0$. The results of a test of the hypothesis that productivity is exogenous with respect to public capital in each country are reported in the third colum 
TABLE 2

Testing for Cointegration between Productivity and Public Capital

\begin{tabular}{|c|c|c|c|}
\hline Country & Hypothesis & trace & $\lambda-\max$ \\
\hline$\ldots \ldots$ & $\ldots \ldots$ & $\cdots$ & $\cdots$ \\
\hline$\cdots \cdots$ & $\begin{aligned} r & =1\end{aligned}$ & 3.69 & 3.69 \\
\hline \multicolumn{4}{|c|}{-} \\
\hline - . & $r=1$ & 1.17 & 1.17 \\
\hline \multicolumn{4}{|c|}{-} \\
\hline ...... & $r=1$ & 7.07 & 7.07 \\
\hline \multicolumn{4}{|l|}{$G R$} \\
\hline & $r=0$ & $27.74 \star$ & $20.67 \star$ \\
\hline & $\begin{array}{l}r=1 \\
\quad-1\end{array}$ & 0.01 & 0.01 \\
\hline \multicolumn{4}{|l|}{$U K$} \\
\hline & $r=0$ & $17.05 * \pi *$ & $17.04 * * *$ \\
\hline$\ldots \ldots$ & $\ldots$ & $\cdots$ & $\cdots$ \\
\hline$\ldots$ & $\ldots$ & $\cdots$ & $\cdots \cdots$ \\
\hline
\end{tabular}

* significant at the 1 percent level

** significant at the 5 percent level *** significant at the 10 percent level

Statistical significance evaluated using the critical values reported in Osterwald-Lenum (1991) Table III. VECM contains a constant vector $\mu_{0}$ and 4 lags of $\Delta y(t)$ except for the US system which requires 5 lags of $\Delta y(t)$ to achieve white noise residuals. The data definitions and avallable samples are given in Table 1 . 
Table 3. For the US and France we can reject the hypothesis that productivity is exogenous with respect to public capital at the 1 percent level, and for Germany we can reject the hypothesis that productivity is exogenous with respect to public capital at the 7 percent level. For Britain we cannot reject the hypothesis, which is necessary but not sufficient for the exogeneity of productivity with respect to public capital, that $\phi_{1}=0$. Ericsson shows that exogeneity requires, in addition to $\phi_{1}=0$, that productivity growth not be Granger caused by lagged growth in public capital. This hypothesis is tested using the likelihood ratio test. We find, but do not report in Table 3 , that we can reject at the 1 percent level the hypothesis that productivity growth in Britain is not Granger caused by lagged public capital growth. Notwithstanding the ex ante plausibility of the hypothesis that productivity is exogenous with respect to public capital, there is substantial statistical evidence against this hypothesis in the US, French, German, and British data. However, there is also evidence, in the form of significant adjustment coefficients $\varphi_{2}$ in the German and British data, that public capital is not exogenous with respect to measured productivity. Moreover, Granger causality test on the US and French data indicate that lagged productivity helps to forecast future public investment. We conclude that the structural relationship between public capital and productivity needs to be further investigated in light of the cointegration and causality results reported in this paper. 
Johansen VECM Estimates of $\gamma$ and $\varphi$

\begin{tabular}{|c|c|c|c|}
\hline Country & $\stackrel{r}{1-r a t i o}$ & $\varphi_{1}$ & $\begin{array}{c}\varphi_{2} \\
1 \text {-ratio }\end{array}$ \\
\hline$\ldots \ldots$ & $\ldots \ldots$ & 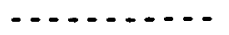 & - \\
\hline$\ldots \ldots$ & 0.37 & $\begin{array}{l}-1.67 \\
-1.67\end{array}$ & -0.10 \\
\hline \multicolumn{4}{|l|}{ US } \\
\hline & 12.75 & 12.59 & 2.01 \\
\hline$\ldots$ & 0.39 & -0.75 & -0.01 \\
\hline \multicolumn{4}{|l|}{$F R$} \\
\hline & 24.08 & 30.69 & 0.01 \\
\hline$\ldots$ & 0.48 & -1.31 & 0.43 \\
\hline \multicolumn{4}{|l|}{$G R$} \\
\hline & 13.13 & 3.23 & 9.23 \\
\hline$\cdots-\ldots$ & 0.41 & 0.06 & 0.27 \\
\hline \multicolumn{4}{|l|}{ UK } \\
\hline$\ldots$ & $\ldots \ldots$ & $\ldots$ & $\ldots \ldots$ \\
\hline$\cdots-\cdots$ & $\ldots \ldots$ & $\cdots+-\cdots$ & $\cdots-\cdots$ \\
\hline
\end{tabular}

The likelihood ratio statistic is distributed as a chi-square randon variable 1 degree of freedom. Critical values are

$$
\begin{aligned}
& 2.71 \text { at the } 10 \text { percent level } \\
& 3.84 \text { at the } 5 \text { percent level } \\
& 6.63 \text { at the } 1 \text { percent level }
\end{aligned}
$$


REFERENICES

Aschauer, D., "Is Public Expenditure Productive?" Journal of Monetary Economics, 1989 .

Barro, R., "Government Spending in a Simple Model of Endogenous Growth." Journal of Political Economy, 1990.

Barro, R., G. Mankiw and X. Sala-i-Martin, "Capital Mobility in Neoclassical Models of Growth." NBER Working Paper No. 1206.1992. ........... and X. Sala-i-Martin, Economic Growth, manuscript, 1991.

Blanchard, 0 , and S. Fischer, Macroeconomics, 1990.

Baldwin, R., "The Growth Effects of 1992", Economic Policy, 1992.

Campbell, J. and P. Perron, "What Macroeconomists Should Know About Unit Roots," NBER Macroeconomics Annual, 1991.

Clarida, R. and R. Findlay, "Government, Trade, and Comparative Advantage," American Economic Review Papers and Proceeding, May 1992.

......... "After Maastricht: Government. Trade, and International Gpit Mobility," mimeo, Columbia University. 1993.

Ericsson, N., "Cointegration, Exogeneity, and Policy Analysis." International Finance Discussion Paper NO. 1415. 1991.

Feldstein, M. and C. Horioka, "Domestic Saving and International Capital Flows," Economic Journal (90), 1980.

......., and P. Bacchetta, "National Saving and International Investment," in Bernheim and Shoven, eds.. National Saving and Economic Performance, Chicago Press. 1991. 
Ford, R., and P. Poret, "Infrastructure and Private Sector Productivity," OECD Economic Studies, 1991.

Granger, C. and P. Newbold, "Spurious Regression in Economics," Journal of Econometrics, 1974.

Johansen, S., "Maximum Likelihhod Estimation of Cointegrating

Systems," Econometrica, 1991.

............ "Cointegration in Partial Systems, "Journal of

Econometrics, 1992.

Helliwell, J., "Trade and Technical Progress," NBER Working Paper No. 4226, 1992.

Kaldor, N., "Capital Accumulation and Economic Growth" in F. Lutz and D. Hague, eds.. The Theory of Capital, New York: St. Martins. 1961.

Mankiw, G., D. Romer and D. Weil, "A Contribution to the Empirics of Economic Growth," Quarterly Journal of Economics, 1992.

Obstfeld, M. "Capital Mobility in the World Economy," Carnegie-Rochester Conference on Public Policy, 1987. 